clinical trials that wouldn't otherwise have happened, says Leif Ellisen, a geneticist who helps lead the hospital's cancer testing programme. For example, its broad genetic test detects a mutation in a gene called $B R A F$ that is already known to be commonly mutated in metastatic melanoma. Finding such mutations in people with lung and colon cancer made it possible to put them in a trial of an experimental treatment targeting that gene, Ellisen explains.

Basic research should also benefit from the NHS programme, says Peach. Researchers will have access to consenting patients' genetic data as well as to medical records of the outcomes of the treatment. These data could reveal how drugs targeting one molecular pathway are affected by mutations in another gene, says Andy Futreal, a cancer geneticist at the Wellcome Trust Sanger Institute in Hinxton, UK, and an adviser to the programme.

Peach hopes that the first phase of the cancer programme will pave the way for expanding genetic testing to more patients and other conditions, such as diabetes, AIDS and even psychiatric disorders. Cancer offers a good testing ground for personalized medicine, because numerous targeted therapies already exist, but "there's no reason why this should be restricted to cancer", says Peach.

Fabrice André, who runs a similar cancer diagnostic programme that has so far been offered to about 100 patients at the Gustave Roussy Institute in Villejuif, France, says the NHS programme could point the way to implementing personalized medicine across an entire population. "It can really change the landscape of how molecular testing is being done for cancer," he says. "If they succeed, then it's going to be a major step forward."

\title{
Global disease fund hit by cash crisis
}

\section{Pledges fall short for fight against AIDS, TB and malaria.}

\section{BY DECLAN BUTLER}

$\mathrm{G}$ oing into a meeting of donors in New York City on 5 October, the Global Fund to Fight AIDS, Tuberculosis and Malaria was aiming high. Its representatives hoped to raise US $\$ 20$ billion, enough to scale up the campaign against these diseases. But countries pledged just $\$ 11.7$ billion for 201113 , although the fund still hopes to raise the minimum $\$ 13$ billion needed to maintain its current programmes.

The fund accounts for a quarter of all international financing to fight AIDS, two-thirds of that for tuberculosis, and three-quarters of that for malaria. By its own estimates, it has saved 4.9 million lives since its creation in 2002.

"It's a classic good news, bad news story," says Andrew Hurst, a spokesman for the fund, which is based in Geneva, Switzerland. The pledge marks a $20 \%$ increase on the $\$ 9.7$ billion raised for the period 2008-10 at its last fundraising meeting in Berlin in 2007. Given today's economic climate, the outcome could have been far worse, he says.

The bad news is that the fund has not raised enough cash to reduce disease burdens among the poor by 2015, to levels to which countries have committed in the UN Millennium Development Goals. In the run-up to the meeting, the fund had estimated that it needed $\$ 20$ billion to start making serious progress on this task, whereas $\$ 13$ billion would buy only minimal burden reductions (see 'The human cost').

The poor funding outcome starkly highlights a chronic structural weakness of the

Global Fund: its narrow base of donors. Just a couple of dozen countries donated, and a mere seven countries gave more than $\$ 100$ million - the United States, France, Germany, Japan, Canada, Norway and Australia. Three other countries traditionally supportive of the fund - the United Kingdom, the Netherlands and Sweden - were unable to officially pledge at the meeting because of the timing of national budgets, but are likely to commit sums that will allow the Global Fund to reach its \$13-billion lower target. Yet dozens of rich countries, including Italy, Spain and Saudi Arabia, gave nothing. The fund is seeking to persuade more nations to pledge, says Hurst, but admits that "we still have some way to go".

For the first time in its history, the fund will now be forced to reject otherwise-solid new proposals from recipient countries, and trim others. "Today marks a sad turning point in the fight against AIDS, TB and malaria, as world leaders have officially underfinanced the Global Fund," says Jennifer Cohn, HIV/AIDS policy adviser at Médecins Sans

$\rightarrow$ NATURE.COM

Who pledged?

How much?

go.nature.com/ekhexd
Frontières in Geneva.

"This decision will result in the deaths of millions of people from otherwise treatable diseases." -

\section{THE HUMAN COST}

Estimating the effect of different funding scenarios for 2011-13 shows that although US $\$ 20$ billion would allow a significant scale-up of activities, $\$ 13$ billion yields far less progress towards internationally agreed targets for 2015 .
Number of people to get antiretrovirals for HIV/AIDS

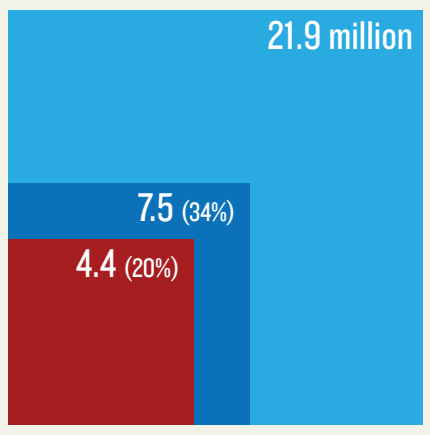

Number of insecticidal bednets to tackle malaria

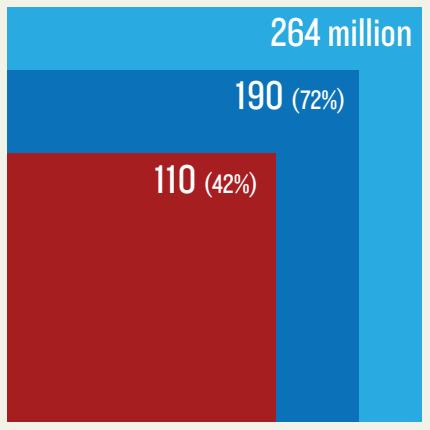

HIV-positive pregnant women on antiretrovirals

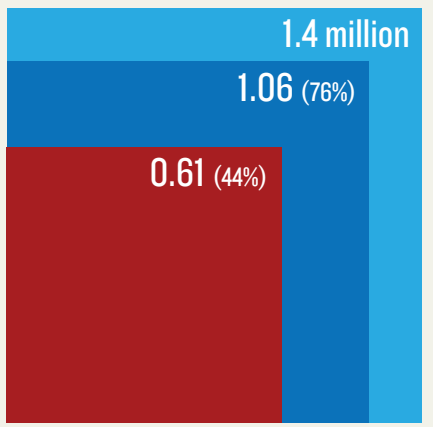

Number of AIDS orphans given support

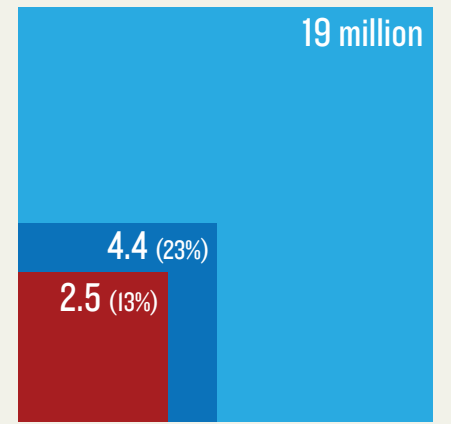

